\title{
Analysis and Interpretation of the Field and Laboratory Geophysical Measurements of Black-Sand Beach Deposits, East Rosetta, Egypt
}

\author{
Mohamed A. El-Sadek, Ahmed A. Ammar, and Sayed A. Elkhateeb \\ Exploration Division, Nuclear Materials Authority, P.O. Box 530, Maadi, Cairo, Egypt \\ Correspondence should be addressed to Mohamed A. El-Sadek, elsadek_eg@yahoo.com \\ Received 13 November 2011; Accepted 3 February 2012 \\ Academic Editor: Francesco Soldovieri
}

Copyright ( 2012 Mohamed A. El-Sadek et al. This is an open access article distributed under the Creative Commons Attribution License, which permits unrestricted use, distribution, and reproduction in any medium, provided the original work is properly cited.

\begin{abstract}
The present study deals with the analysis and interpretation of the results of field geophysical survey and laboratory geophysical measurements. The study of the magnetic and electrical methods was selected because the beach sands contain many minerals that have magnetic and electric properties. Analysis and interpretation of the field and laboratory magnetic and geoelectric maps demonstrated that the investigated beach-alluvial deposits can be subdivided according to their magnetic and geoelectric properties into three main zones striking nearly parallel to the shoreline of the Mediterranean Sea at the study area. The northern zone is more enriched in black sands than the central or southern zones. Field and laboratory magnetic susceptibility measurements provided very useful maps for the concentration of heavy minerals. The deep-seated magnetic response was calculated at an average depth of $239.6 \mathrm{~m}$, while the near-surface magnetic responses were computed at average depths of 9.1, 57.9, and 81.8 m, respectively. The correlation between the geophysical features, recorded on the total magnetic field intensity, the electric resistivity, the IP chargeability, and the calculated metal factor, was found to agree to a great extent. The heavymineral concentration was found to decrease with depth. However, the heavyminerals show parallel zones below the surface, suggesting similar sedimentation environments.
\end{abstract}

\section{Introduction}

The alluvial-beach placer deposits, East Rosetta, Mediterranean Sea Coast, Northern Egypt, are known for their enhanced natural radiation environment, due to the presence of radiogenic heavy minerals, such as monazite and zircon, which contain $T h$ and $U$ in their chemical composition [1]. The placer deposits are well known as sources for economic heavy minerals and nuclear raw materials, in addition to their importance in many of the strategic, metallurgical, and engineering industries. The mineralogical analyses identified six main heavy mineral sands accompanied by traces of cassiterite and gold as well as some minerals of rare earth elements (REEs). According to their relative frequencies, the six heavy minerals include ilmenite, magnetite, zircon, monazite, garnet, and rutile. The study area $\left(30^{\circ} 32^{\prime} 10^{\prime \prime} \mathrm{E}\right.$ and $30^{\circ} 34^{\prime} 08^{\prime \prime} \mathrm{E}$ long.; $31^{\circ} 26^{\prime} 59^{\prime \prime} \mathrm{N}$ and $31^{\circ} 27^{\prime} 59^{\prime \prime} \mathrm{N}$ lat.) extends over a length of $3.0 \mathrm{~km}$, trending in an $\mathrm{E}-\mathrm{W}$ direction along the Mediterranean Sea Coast, with an average width of more than $1.8 \mathrm{~km}$ (Figure 1).

The main objectives of the present study are

(1) evaluation of surface extensions of the beach-alluvial deposits, using field magnetic and susceptibilities survey, as well as laboratory magnetic and geoelectric measurements;

(2) mapping the spatial distribution patterns of zones of heavy mineral concentrations;

(3) identification of the depositional phases;

(4) delineation of the subsurface (shallow and deep seated) magnetic sources.

Figure 2 shows the schematic diagram for all techniques employed in the study area. 


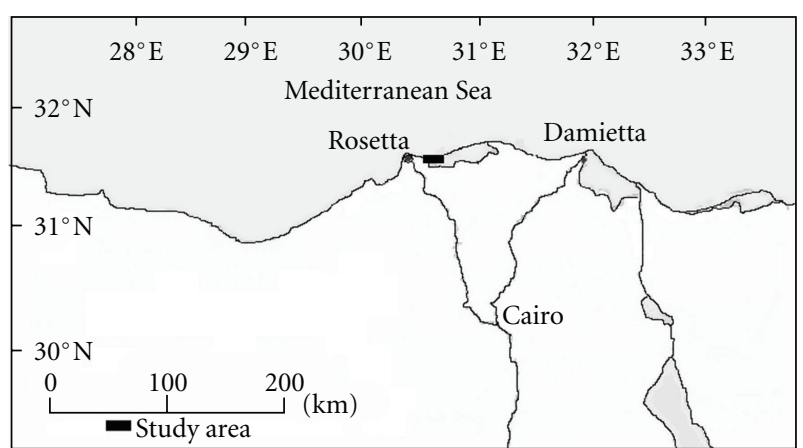

Figure 1: Map of Northern Egypt showing the location of the study area.

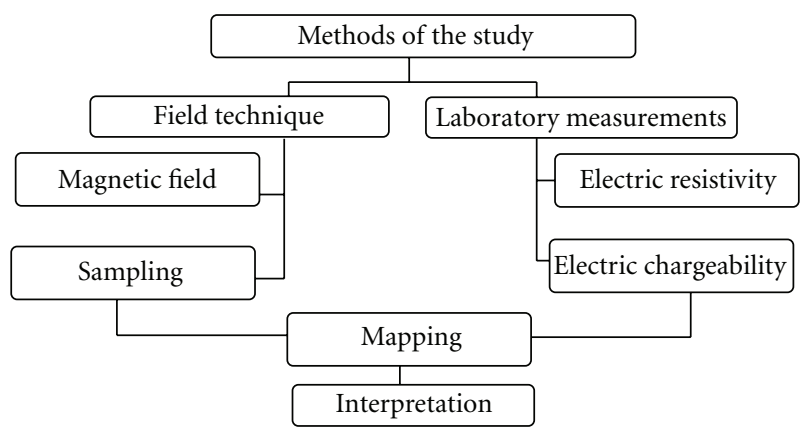

FIgure 2: Schematic diagram for all the techniques in the study area.

Placer sand deposits in the northern Nile Delta, especially in Koam Mashaal area, have received the attention of several researchers since the early years of the 20th century. The most recent researches that carried out studies on these placer sands include Hedrick and Waked [2], Elhadary [3], AbuDiab [4], El-Sadek and Elkhateeb [5], Bakheit [6], Ammar et al. [1], and Moustafa [7]. The study area is a part of the semiarid coastal region which is characterized by its wide plain covered by placer sand deposits.

The placer deposits, East Rosetta, have high mineral productivity, which can be easily mined. El Askary and Frihy [8] identified three depositional phases in the upper $30 \mathrm{~m}$ at Rosetta and Damietta promontories. These are from base to top: transgression, regression, and erosional transgression phases. The beach is generally flat in the Rosetta area, where seawater crosses the beach during winter stormy conditions and high-tide periods [9].

\section{Materials and Methods}

2.1. Ground Magnetic Survey. The ground magnetic survey was conducted along a set of equally spaced $(100 \mathrm{~m})$ parallel traverses oriented N-S, a direction that is perpendicular to the general extension of the Mediterranean Sea Coast in the study area. The general strike of the lithological units in the study area was determined according to the general elongation of the black-sand lenses occurring along the Mediterranean Sea Coast, which approximately extends in an E-W direction. Magnetic measurements were made at regular intervals of $10 \mathrm{~m}$. The survey data were tied along one tie line perpendicular to the direction of the survey traverses. A base station was placed at a reference point, selected far from artificial magnetic disturbances within the surveyed area. The total magnetic-intensity measurements, collected at the survey stations, were regarded as positive or negative deviations from the ones at the reference point (base station).

The ground raw magnetic survey measurements were subjected to essential corrections, including diurnal as well as tie-line corrections. On the other hand, the terrain correction was not applied to the magnetic data, since the surveyed area is characterized by its smooth terrain and insignificant elevation differences between survey stations. The geomagnetic correction was calculated at the central point of the study area, where the International Geomagnetic Reference Field (IGRF) reaches 43,519.12 nT, the inclination angle attains $45.89^{\circ}$, and the declination angle equals $2.78^{\circ}$ at $31^{\circ} 27^{\prime} 05^{\prime \prime} \mathrm{N}$ lat. and $30^{\circ} 33^{\prime} 00^{\prime \prime} \mathrm{E}$ long. in October 30, 2001 [10]. The IGRF value was subtracted from the readings of the whole survey stations. The survey data were transformed from the field magnetometer to a desktop computer, where data reduction was performed by using a set of computer softwares (Microsoft Excel, MDA1-Ver.1.97 and MDA2Ver.1.97).

The total magnetic-field intensity measurements were carried out using a portable proton-precession magnetometer, model PMG-1, Geofyzika Brno, Czech Republic, having a sensitivity of $0.1 \mathrm{nT}$ and a measuring range from 25,000 to 100,000 nT (PGM-1 Manual, 1997). Another magnetometer of the same type was used as a base station for automatic monitoring and recording of diurnal variations in the Earth's magnetic field. The measuring time was set for one minute at the base station as a matter of diurnal variation and storage capacity of the instrument.

The ground magnetic survey data, including spectral frequency analysis and isolation of magnetic anomalies, were carried out using the software of Magnetic Data Analysis (MDA2-Ver 1.97; [11]), which is based on Filon Fourier Transform. This software designs the suitable filter and separates the regional and residual magnetic components.

\subsection{Field and Laboratory Magnetic Susceptibility Measure-} ments. The pocket susceptibility meter, type KT-6, Geofyzika Brno, Czech Republic, is designed for quick-field measurements of magnetic susceptibility of outcropping rocks, drill cores, and larger pieces of rocks. The sensitivity of the equipment is $1 * 10^{-5} \mathrm{SI}$ units, and the measuring range varies from -999 to 9,999 SI units, with automatically switched accuracies: 9.99, 99.9, and 999 [12]. It was used to determine the magnetic susceptibility both in field and laboratory. The samples were friable with size about 234 grams. The black-sand samples were put in plastic cylindrical containers of $11.0 \mathrm{~cm}$ in diameter and $6.0 \mathrm{~cm}$ in height. The magnetic susceptibility measurements were applied to surface field measurements and quartered 966 representative samples, taken from large samples, collected from the field up to $50 \mathrm{~cm}$ in depth. The collected samples were taken along 


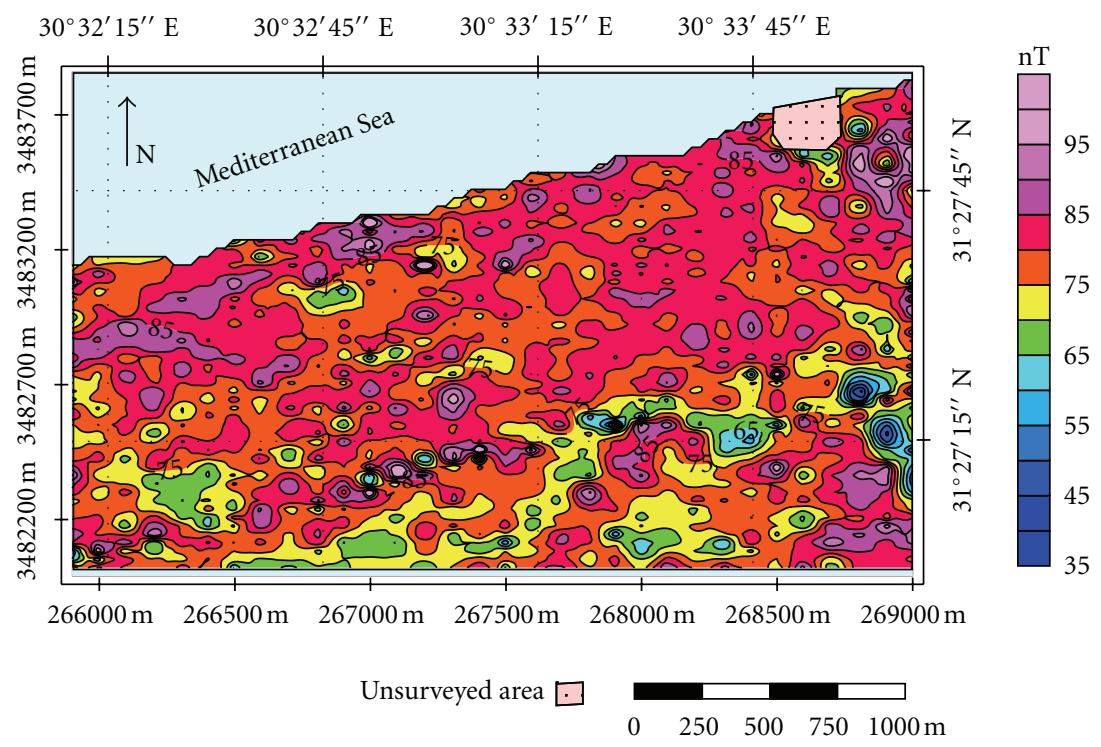

Figure 3: Filled colour contour map of the total magnetic intensity of Koam Mashaal area, East Rosetta, Mediterranean Sea Coast, Northern Egypt.

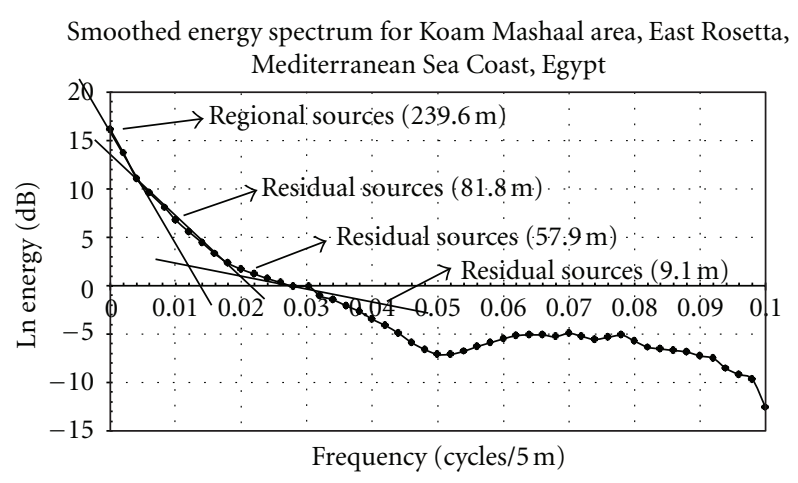

FIGURE 4: The local power spectrum of the ground magnetic data for the study area.

equally spaced stations, $50 \mathrm{~m}$ apart, at 32 parallel equally spaced $(100 \mathrm{~m})$ profiles. These profiles were oriented in an $\mathrm{N}-\mathrm{S}$ direction and spaced at $100 \mathrm{~m}$ intervals, covering an area of about $5.4 \mathrm{~km}^{2}$.

A 12-channel global positioning system (GPS) instrument was used to set up the survey grid with a Universal Transverse Mercator (UTM) coordinate system, using World Grid (WG84) as datum. All samples were put in plastic bags and labelled by their UTM positions.

2.3. Laboratory Geoelectric Measurements. The laboratory geoelectric (resistivity and chargeability) measurements were applied to the 966 quartered representative samples, taken from large samples collected in the field at depths up to $50 \mathrm{~cm}$. The large samples were taken along 32 equally spaced (100 $\mathrm{m}$ apart) profiles, at equally spaced (50 $\mathrm{m}$ apart) stations. These profiles were oriented in an N-S direction, covering about $5.4 \mathrm{~km}^{2}$. The samples were taken by pushing a rigid plastic tube $(5 \mathrm{~cm}$ in diameter and $70 \mathrm{~cm}$ in length) into the ground up to $70 \mathrm{~cm}$ in depth. The collected samples were quartered using John's splitter.

The ELREC-2 instrument, induced polarization of low power system (IP-L system), manufactured by IRIS Instruments, France, was used in this study to measure the electric resistivity and induced polarization (IP) parameters on the 966 quartered representative samples collected from the field as previously mentioned. The measuring system consists of three units: a sample holder frame, an IP-L low-power time domain transmitter, and an ELREC-2 as a time-domain IP receiver [13]. The sample holder was modified to be compatible with friable sand samples. The new holder is a rigid plastic tube, with a plastic piston to compress the friable sand. This plastic tube possesses four-minute holes at equal distances of $4.0 \mathrm{~cm}$, as a Wenner array, and fourelectrode terminals for connecting the electric current. The two current electrodes are connected to the external holes and the two potential electrodes to the central holes.

\section{Results and Discussion}

3.1. Magnetic Survey. Environmental magnetism deals with the magnetic properties of natural iron oxides as a tool for understanding and interpreting the processes in sedimentary systems [14-16]. It was applied successfully in modelling sediment loads in fluvial systems $[17,18]$. The intensity of magnetization of a rock is largely dependent upon the amount, size, shape, and distribution of its content of ferromagnetic minerals that usually represent only a small proportion of its mineral composition. Much qualitative information may be derived from magnetic contour maps. Such qualitative interpretation may be greatly facilitated by the use of digital image-processing techniques, similar to those used in the display of remotely sensed data [19]. The corrected ground magnetic data were subjected to various 


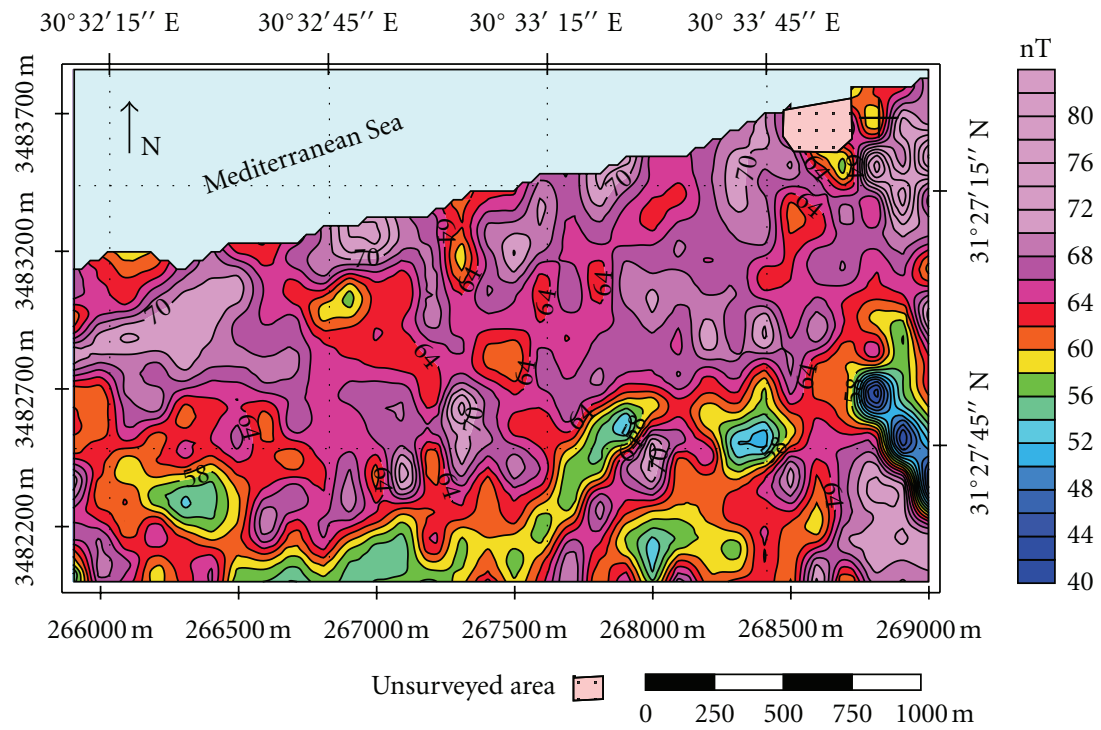

FIGURE 5: Filled colour contour map of the regional component of magnetic-field intensity of Koam Mashaal area, East Rosetta, Mediterranean Sea Coast, Northern Egypt at an average depth $(h)$ of $239.6 \mathrm{~m}$, contour interval $=2 \mathrm{nT}$.

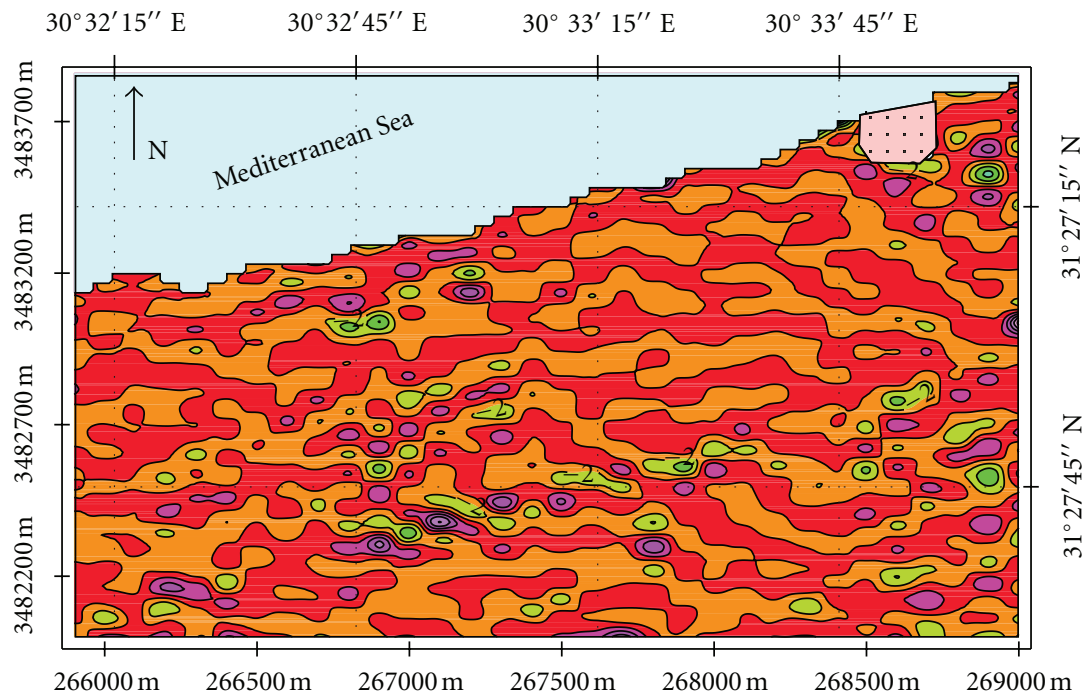

Unsurveyed area

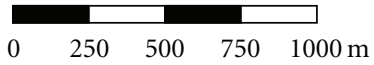

Figure 6: Filled colour contour map of the residual component of magnetic-field intensity of Koam Mashaal area, East Rosetta, Mediterranean Sea Coast, Northern Egypt at an average depth $(h)$ of $9.1 \mathrm{~m}$, contour interval $=2 \mathrm{nT}$.

techniques of analysis in order to get qualitative and quantitative parameters that can well describe the subsurface magnetic sources and consequently guide the exploratory drilling for the buried heavy mineral lenses in the study area. These techniques involved the application of spectral analysis and matched filtering.

3.2. Spectral Analysis of the Ground Magnetic Survey Data. Frequency analysis of the potential field data using the computer software that implements the fast Fourier transform (FFT) has now become a routine practice. The fast Fourier transform is a computational tool which facilitates signal analysis such as power spectrum analysis and filter simulation by means of digital computers. It is a method for efficiently computing the discrete Fourier transform of a series of data samples. It has become a widely used tool for interpretation of potential field data, especially for depth estimation. This approach has been developed by many workers (e.g., [20-22]). However, it was proved that the 


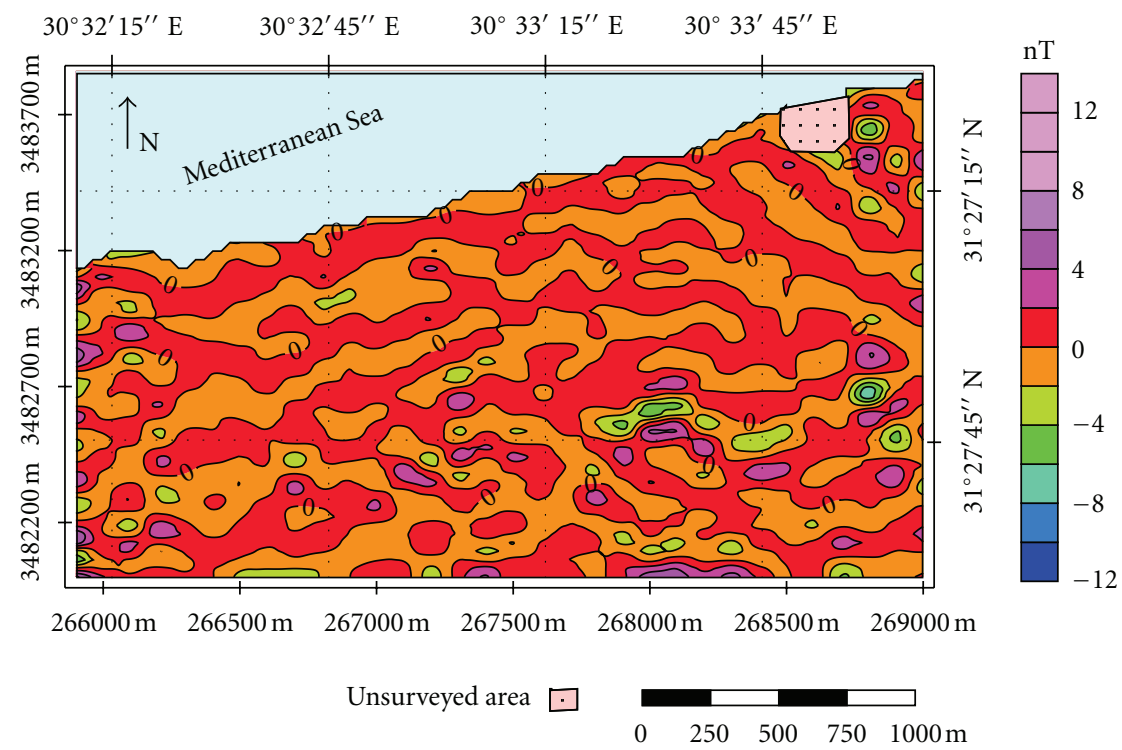

FIGURE 7: Filled colour contour map of the residual component of magnetic-field intensity of Koam Mashaal area, East Rosetta, Mediterranean Sea Coast, Northern Egypt at an average depth $(h)$ of $57.9 \mathrm{~m}$, contour interval $=2 \mathrm{nT}$.

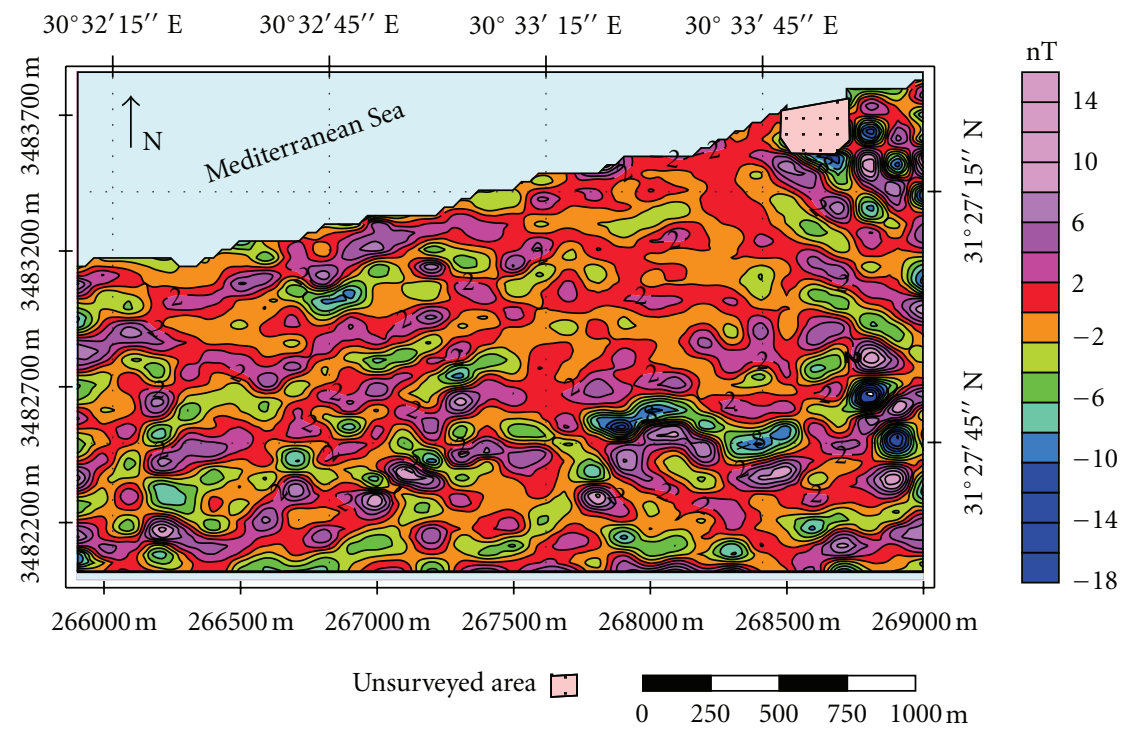

Figure 8: Filled colour contour map of the residual component of magnetic-field intensity of Koam Mashaal area, East Rosetta, Mediterranean Sea Coast, Northern Egypt at an average depth $(h)$ of $81.8 \mathrm{~m}$, contour interval $=2 \mathrm{nT}$.

FFT introduces unacceptable distortions at high frequencies, which describe the response of shallow sources. Accordingly, the interpretation of such sources using FFT is not very reliable [23]. The use of the filon Fourier transform in the spectral analysis of potential field data decreases the distortions in the high-frequency range and thus enables reasonable depth estimates to shallow sources, which are of considerable interest in mineral exploration. Figure 4 shows the local power spectrum of the ground magnetic data for the study area using the magnetic Data Analysis (MDA) software $[11]$.

3.3. Total Magnetic-Field Intensity Map. The recorded total magnetic-field intensity measurements in the study area ranges from 35 to $115 \mathrm{nT}$. The magnetic intensities are roughly arranged in two zones parallel to the shoreline, orienting in an NW-SE direction (Figure 3). The northern part is mainly characterized by relatively higher values of the total-field magnetic intensity measurements. It is mainly enriched in black sands of a beach lens as well as old sand dunes. The magnetic response is mainly due to the existence of magnetite and other magnetic minerals either on the surface or at very shallow depths. The southern part is mainly magnetically lower in intensity values.

3.3.1. Regional Magnetic-Field Intensity Map. Frequencies of magnetic anomalies could reveal the depths of their magnetic sources. The regional magnetic-field intensity map 


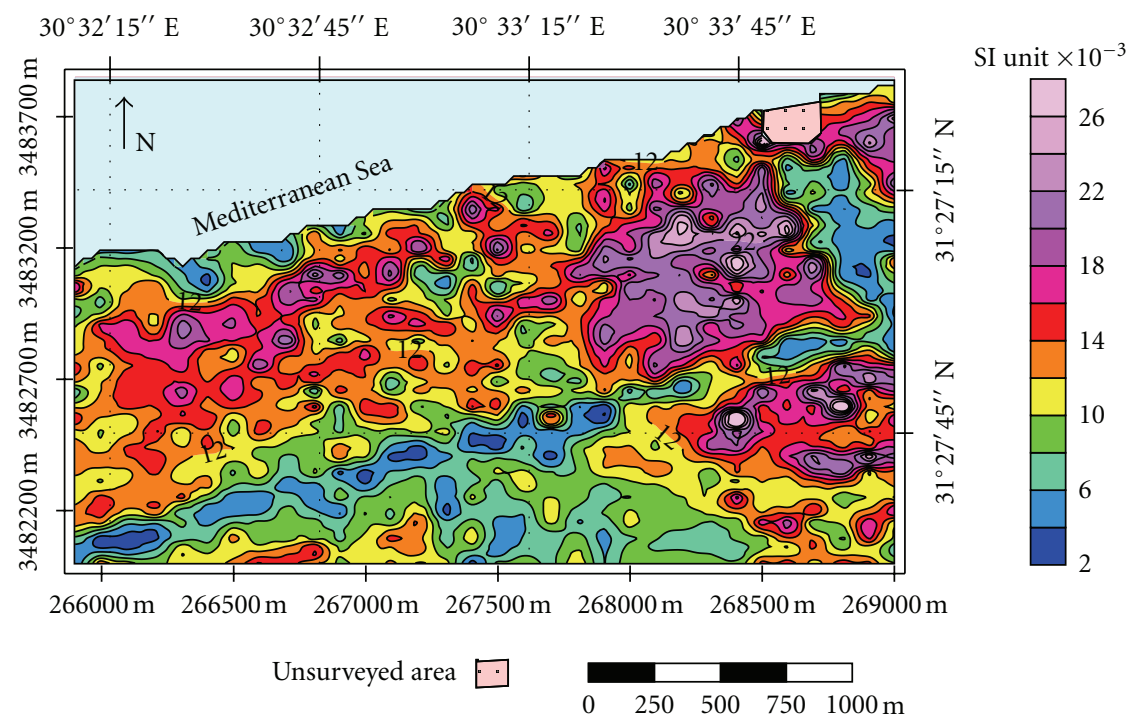

Figure 9: Filled colour contour map of field magnetic susceptibility $(\mathrm{kF})$ measurements, Koam Mashaal area, East Rosetta, Mediterranean Sea Coast, Northern Egypt. Contour interval $=2 * 10^{-3}$ SI unit.

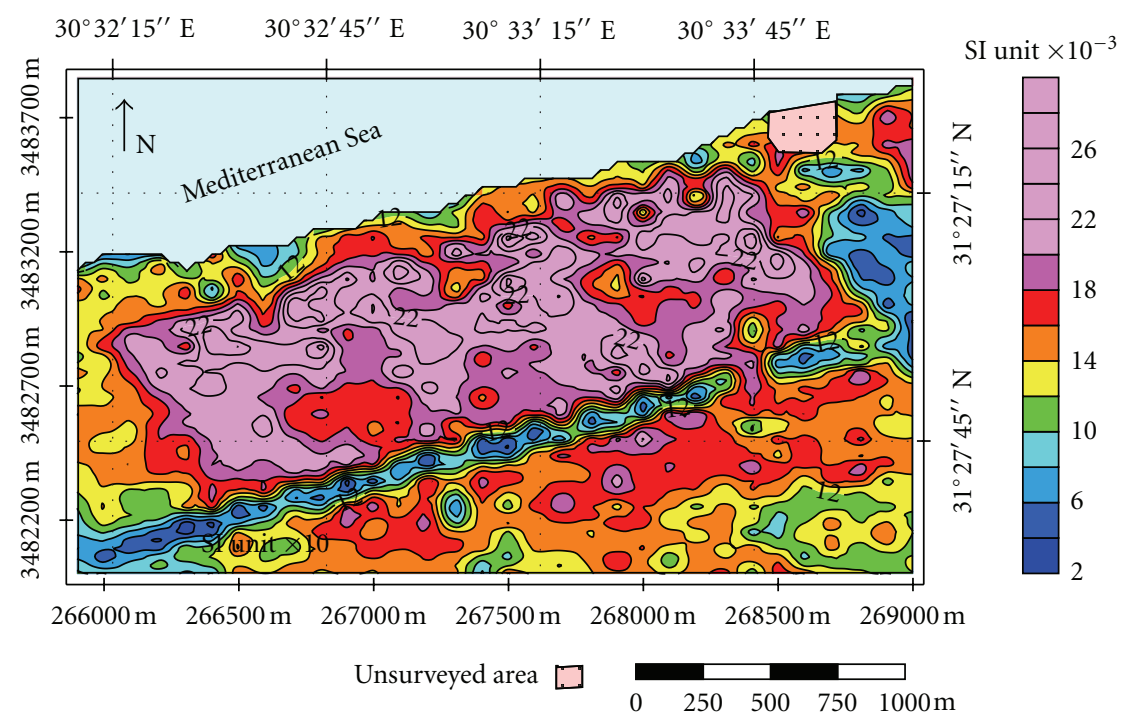

FIGURE 10: Filled colour contour map of laboratory magnetic susceptibility (kL) measurements on samples, Koam Mashaal area, East Rosetta, Mediterranean Sea Coast, Northern Egypt. Contour interval $=2 * 10^{-3}$ SI unit.

(Figure 5) represents the relatively deep-seated magnetic response of the black-sand beach and dune deposits, at an average depth of $239.6 \mathrm{~m}$ (Figure 4). Figure 5 shows that the study area could be also divided into two main zones according to magnetic causative sources. The first zone, located in the northern part of the study area, is characterized by its high magnetic-amplitude anomalies, with low frequencies and long wavelengths, which refer to deep-seated lenses of black-sand deposits. It is also characterized by high to very high magnetic response, ranging in amplitude from $76 \mathrm{nT}$ to $88 \mathrm{nT}$. The other zone, located in the southern part of the study area, is characterized by variations in magnetic responses from low to very high (64 nT to $88 \mathrm{nT})$, with higher frequencies and shorter wavelengths. The high and low magnetic bands, within the second zone, are arranged into elongated stripes oriented in the NE-SW direction.

3.3.2. Residual Magnetic-Field Intensity Map. An important interpreting technique in geophysical exploration is the residual mapping, in which local anomalies are separated from regional ones. According to Burger [24], the definition of residual depends on the exploration target. The residual magnetic intensity contour maps (Figures 6, 7, and 8) represent the magnetic responses of the black-sand deposits at various depths of $9.1,57.9$, and $81.8 \mathrm{~m}$, respectively (Figure 4). The magnetic-field intensity ranges from $25 \mathrm{nT}$ to $45 \mathrm{nT},-40$ to $30 \mathrm{nT}$, and -16 to $12 \mathrm{nT}$ at the three depths, 


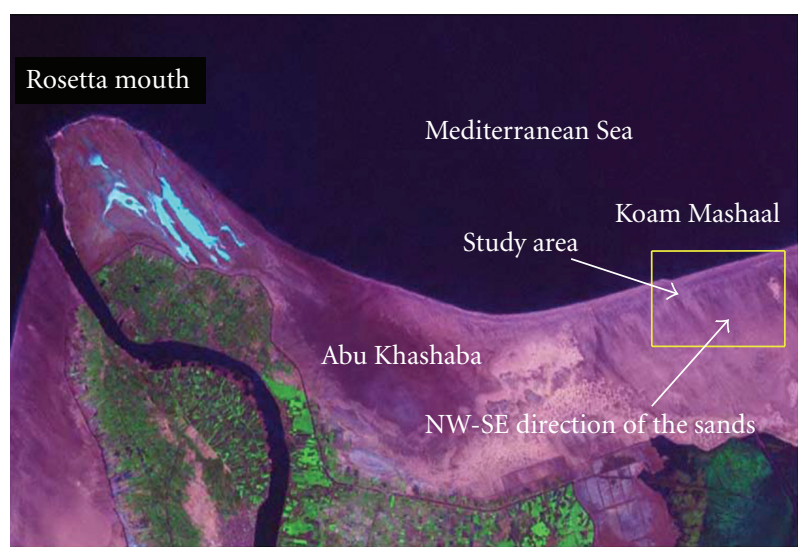

FIgURE 11: Northern Egypt Landsat colour composite image showing the location of the studied Koam Mashaal beach area, East Rosetta, Mediterranean Sea Coast.

respectively. The magnetic zones are elongated and roughly parallel to the shoreline. The magnetic zones are almost similar at the three depths, suggesting similar sedimentation environment. The magnetic intensity at $81.8 \mathrm{~m}$ depth is much lower than the shallower depths $(9.1 \mathrm{~m}$ and $57.9 \mathrm{~m})$.

3.4. Magnetic Susceptibility Measurements. As a result of the presence of the earth's magnetic field, rocks containing magnetic minerals show induced magnetizations. The constant of proportionality between the inducing field and the magnetization is known as the magnetic susceptibility $(k)$. The intensity of magnetization $(I)$ is related to the inducing magnetic field $(H)$ through a constant of proportionality $(k)$ :

$$
I=k H .
$$

The magnetic susceptibility $(k)$ is a measure of the ease by which the material can be magnetized. It is a dimensionless quantity. Magnetic susceptibility can take on positive or negative values. Positive values imply that the induced magnetic field $(I)$ is in the same direction as the inducing field $(H)$. Negative values imply that the induced magnetic field is in the opposite direction as the inducing field. The magnetic susceptibilities of paramagnetic and diamagnetic materials are generally extremely small. Although susceptibility is unitless, its values differ depending on the unit system used to quantify $H$ and $I$. The international system of units (SI), based on the meter, kilogram, second, and ampere (mksa), was used in the present study $[19,25]$. Based on the magnetic susceptibility, the solid materials can be classified into diamagnetic, paramagnetic, and ferromagnetic. In diamagnetic, $k$ has low and negative values. Paramagnetic materials have low and positive $k$ values. Ferromagnetism is a cooperative phenomenon observed in metals like iron, nickel, and cobalt. Ferromagnetic behaviour is characterized by high positive susceptibilities and strong magnetic properties [26]. The intensity of magnetization of rocks can be determined in two different ways: by measuring the magnetic field produced either by a rock sample or by measuring the effect of the sample on the inductance of an electromagnetic circuit [27].
3.4.1. Field Magnetic Susceptibility ( $k_{\mathrm{F}}$ ) Measurements. Magnetic susceptibility $(\mathrm{kF})$ can be measured easily, fast, and with high sensitivity in the field by using pocket susceptibility meter, type KT-6. The measurements of field magnetic susceptibility attain their maximum values reaching about $38.0 * 10^{-3}$ SI units in the northeastern part of the study area, in the form of a great anomaly running parallel to the shoreline. The minimum $\mathrm{kF}$ value reaching $1.52 * 10^{-3} \mathrm{SI}$ units forms an elongated narrow zone, parallel to the shoreline, roughly in the centre of the study area, where an old dry excavated drainage channel is existing (Figure 9). The mean value of $\mathrm{kF}$ in the study area reaches $12.2 * 10^{-3} \mathrm{SI}$ units. Interestingly, Figures 8 and 9 clearly demonstrate that some of the relatively high residual magnetic anomalies correspond to the relatively low magnetic susceptibility measurements; this indicates that the heavy minerals increase with depth.

\subsubsection{Laboratory Magnetic Susceptibility ( $k \mathrm{~L}$ ) Measurements.} The measurements of laboratory magnetic susceptibility $(\mathrm{kL})$ attain their maximum value reaching about $28.6 * 10^{-3} \mathrm{SI}$ units in the central northeastern part of the area under study in the form of a great anomaly running parallel to the shoreline (Figure 10). The minimum kL value reaching $2.16 * 10^{-3}$ SI units is situated in the central southern part of the study area, which represents an old dry excavated drainage channel. The mean value of $\mathrm{kL}$ in the study area reaches $15.67 * 10^{-3}$ SI units.

The filled colour contour maps for field and laboratory magnetic susceptibility measurements (Figures 9 and 10, resp.) show great similarity between each other, especially for the positions of the black-sand lenses. Some of the delineated high magnetic susceptibility anomalies are circular in shape and others are elongated, either parallel to the shoreline or perpendicular to it. The highest levels of magnetic susceptibility are located nearly in the central part and in the north-eastern corner of the study area. These levels are associated with the eastern side of the major lens and the old sand dunes. The lowest levels of magnetic susceptibility are located in different places: close to the shoreline, southwards, and along the dry man-excavated drainage channel. The intermediate magnetic susceptibility level is distributed all over the remaining surface of the study area.

From the visual examination of all geophysical magnetic contour maps, it is noticed that the contours are elongated in two main directions, one parallel to the seashore, that is, in the $\mathrm{N} 75^{\circ} \mathrm{E}$ direction, and the other is oriented in the NWSE direction. The values always point to low concentrations of heavy minerals towards the shore line and to the south of the study area. These observations could be interpreted as follows.

When the area is covered by standing sea water and its slow motion in winter seasons, the denser heavy minerals go down and the light ones float up by gravity. In the summer seasons when the seawater retreats, and the wind blows in an NW-SE direction; the light sand minerals are transported away from the shore to the south of the study area. Hence, the heavy minerals are concentrated by this way in an NW-SE 


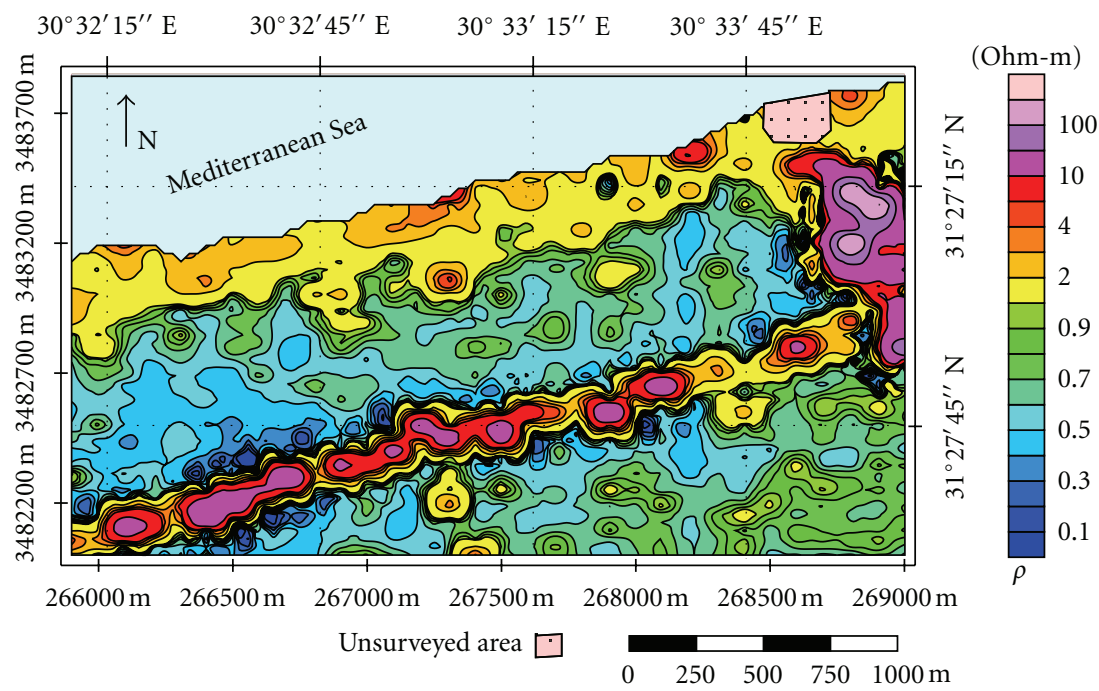

Figure 12: Filled colour contour map of the electric resistivity $(\rho)$ laboratory measurements, Koam Mashaal area, East Rosetta, Mediterranean Sea Coast, Northern Egypt. Contour interval $=0.1 \mathrm{Ohm} \cdot \mathrm{m}$.

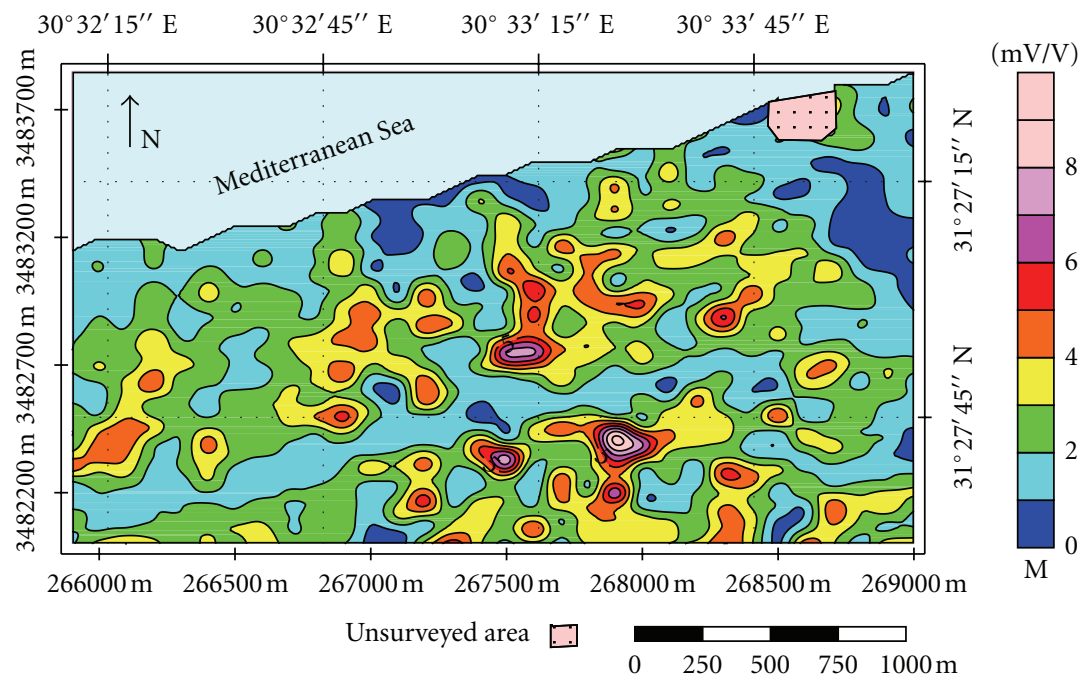

Figure 13: Filled colour contour map of the electric chargeability $(M)$ laboratory measurements, Koam Mashaal area, East Rosetta, Mediterranean Sea Coast, Northern Egypt. Logarithmic contour interval = $1 \mathrm{MV} / \mathrm{V}$.

direction, beside the main action of the sea waves (which act similarly to the action of a Wilfley table on the concentration of the heavy minerals) in a direction parallel to the sea shore $\left(\mathrm{N} 75^{\circ} \mathrm{E}\right.$ direction). There are two other evidences for these two directions. The first one is the satellite image of the Rosetta area (Figure 11), which shows the NW-SE direction of the sands. The second evidence is concerned with the nonsurveyed area, located around the study area, which is occupied by a building that acts as a guard protecting the southeastern part from the wind action and consequently the concentration of heavy minerals.

3.5. Geoelectric Measurements. Electrical measurements are among the most difficult of all geophysical methods to interpret quantitatively, because of the complex theoretical bases of the technique. Electric IP quantitative interpretation is considerably more complex than the electric resistivity method. Much electric IP interpretation is, however, only qualitative [19].

3.5.1. Laboratory Electric Resistivity Measurements. The recorded electric resistivity measurements range from 0.1 to $200 \mathrm{Ohm} \cdot \mathrm{m}$. The electric resistivity map (Figure 12) shows a prominent broad zone of low resistivity values, occupying most of the study area. A central high-resistivity zone, parallel to the shoreline, separates this prominent lowresistivity zone into two subzones. This central zone takes the form of a narrow strip of an elongated shape, trending to the NNW direction. It shows very high electric resistivity values $(>100 \mathrm{Ohm} \cdot \mathrm{m})$, especially in its eastern part, where 


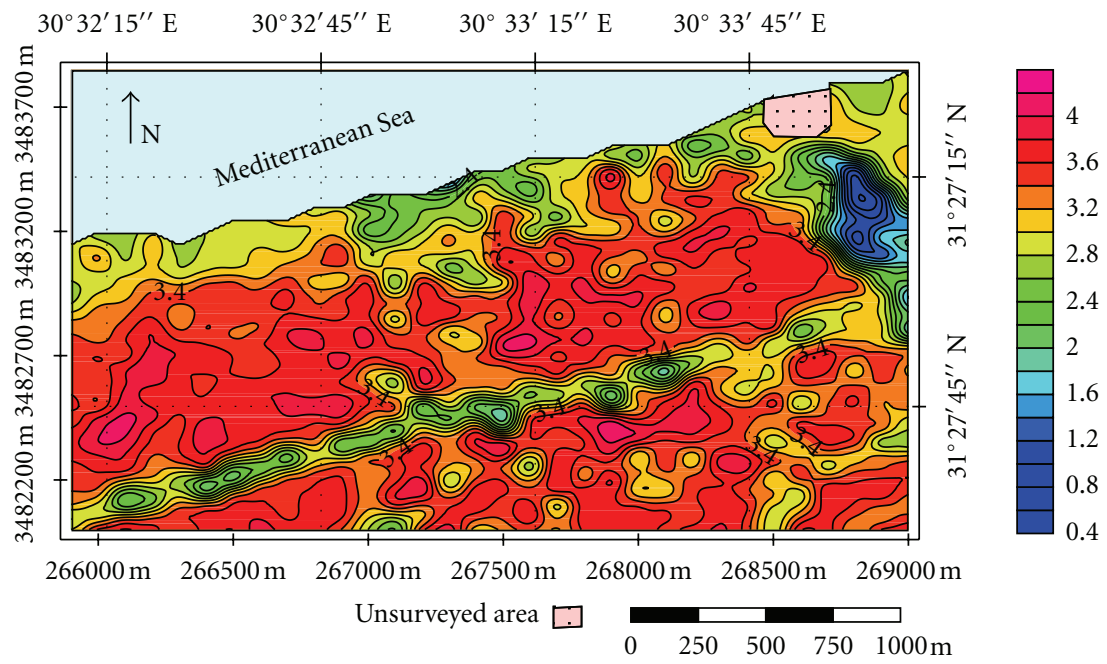

FIGURE 14: Filled colour contour map of the calculated metal factor (MF) values from laboratory measurements, Koam Mashaal area, East Rosetta, Mediterranean Sea Coast, Northern Egypt. Logarithmic contour interval = 0.2.

the old excavated drainage channel exists, as well as in the western part of some old sand dunes. There is also a relatively moderate- to high-electric-resistivity zone (from 1.0 to 10.0 Ohm.m.) delimiting the northern part of the study area, running parallel to the shoreline (Figure 12).

\subsubsection{Laboratory Electric (IP) Chargeability Measurements.} The low electric IP chargeability values agree well with the high electric resistivity values at the narrow zone, located in both central and eastern parts of the study area as well as its northern part (Figure 13). The intermediate- and highelectric-IP-chargeability zones also correspond well with the intermediate- and low-electric-resistivity zones, where the economic heavy mineral deposits occur. Two relatively high-electric-IP-chargeability zones were distinguished at the central northern, and southern parts of the study area, with electric IP chargeability values exceeding $11 \mathrm{mV} / \mathrm{V}$, and they coincide well with the zones of very high concentrations of heavy minerals.

3.5.3. The Calculated Metal Factor. Similar to the distribution of the IP chargeability, and electric resistivity values, the high values of the calculated metal factor (Figure 14) coincide well with high electric IP chargeability and low electric resistivity values. Moreover, they indicate the existence of anomalous zones that occur at the central, northern, and southern parts of the study area, which also agree well with the zones of anomalous concentrations of economic heavy minerals.

\section{Conclusions}

The correlation between the geophysical features recorded on the maps of total magnetic field intensity, magnetic susceptibility, electric resistivity, IP chargeability and calculated metal factor of the study area was found to agree to a great extent. Field and laboratory magnetic and geoelectric maps demonstrate that the investigated beach-alluvial deposits of Koam Mashaal area can be subdivided into three main zones striking nearly parallel to the shoreline of the Mediterranean Sea, Northern Egypt. The northern zone is more enriched in black sands than the central or southern zones. The heavy mineral concentration was found to decrease with depth. However, the heavy minerals also show some parallel zones below the surface, suggesting similar sedimentation environments. The deep-seated magnetic response was interpreted to lie at an average depth of $239.6 \mathrm{~m}$, while the near-surface magnetic responses were interpreted to lie at average depths of 9.1, 57.9, and $81.8 \mathrm{~m}$, respectively. The recorded electric resistivity measurements range from 0.1 to $200 \mathrm{Ohm} \cdot \mathrm{m}$. The high electric IP chargeability values coincide well with the high values of the calculated metal factor, low electric resistivity values, and high magnetic susceptibility values. These tools are very useful and are recommended for the study and investigation of black-sand beach deposits everywhere.

\section{References}

[1] A. A. Ammar, A. S. Sharaaky, A. N. Shahein, M. A. ElSadek, and S. A. Elkhateeb, "Radiolithologic studies on beach and alluvial black-sand deposits, Koam Mashaal area, Egypt, using ground radiospectrometry," in Proceedings of the 1st International Conference on the Geology of Tethys, vol. 1, pp. 125-136, Cairo University, 2005.

[2] J. B. Hedrick and L. Waked, "Heavy minerals, including monazite, in Egypt's black sand deposits," Journal of The LessCommon Metals, vol. 148, no. 1-2, pp. 79-84, 1989.

[3] A. F. Elhadary, Geological, sedimentological and radiometric studies on the black-sand deposits, west Rosetta beach, with emphasis on the heavy economic minerals, Ph.D. thesis, Faculty of Science, Cairo University, Geiza, Egypt, 1998.

[4] A. A. Abu-Diab, Sedimentological studies and economic evaluation of the coastal sand dunes between Elgadia and Idko, Rosetta, Egypt, Ph.D. thesis, Faculty of Science, Mansuora University, Mansuora, Egypt, 2001. 
[5] M. A. El-Sadek and S. A. Elkhateeb, "Magnetic susceptibility of black-sand beach deposits," Koam Mashaal area, east Rosetta, Egypt, Internal Report Series, NMA-IRS-3/2002, Cairo, Egypt, 2002.

[6] A. F. Bakheit, Mineralogy and concentration of economic heavy minerals, northern Delta, Egypt, Ph.D. thesis, Cairo University, Geiza, Egypt, 2004.

[7] M. I. Moustafa, "Chemistry and origin of enigmatic monazite and chevkinite/perrierite in the egyptian black beach sand," Resource Geology, vol. 60, no. 3, pp. 271-287, 2010.

[8] M. A. El Askary and O. E. Frihy, "Depositional phases of rosetta and damietta promontories on the Nile Delta coast," Journal of African Earth Sciences, vol. 5, no. 6, pp. 627-633, 1986.

[9] A. F. Elhadary, Geologic and radiometric investigations on AbuKhashaba deposits, east Rosetta, Egypt, Ph.D. thesis, Geology Department, Faculty of Science, Cairo University, Geiza, Egypt, 1988.

[10] GM. SYS. Program, "Definitive International Geomagnetic Reference Field, Version 1.5," Computation Routines by Mike Gemperle and Rowland B. French, Interface by Pierre Doguin, Northwest Geophysical Associates Inc., 1997.

[11] F. O. Badokhon, Geophysical exploration for oolitic iron deposit extensions in the northern part of Wadi Ash-Shumaysi, Saudi Arabia, Ph.D. thesis, King Abdulazeiz University, Jeddah, Saudi Arabia, 1998.

[12] G. Brno, Instruction Manual of Kappa Meter KT6, Geofyzika Brno, Brno, Czech Republic, 1998.

[13] IRIS Instruments, "ELREC 2 Operating manual, Revised. BRGM \& OYO Joint Venture," IRIS Instruments, Orleans, Cedex 2, France 1993.

[14] R. Thompson and F. Oldfield, Environmental Magnetism, Allen and Unwin, London, UK, 1986.

[15] B. A. Maher, R. Thompson, and M. W. Hounslow, "Introduction," in Quaternary Climates, Environments and Magnetism, B. A. Maher and R. Thompson, Eds., pp. 1-48, Cambridge University Press, Cambridge, UK, 1999.

[16] M. E. Evans and F. Heller, Environmental Magnetism: Principles and Applications of Enviromagnetics, Academic Press, London, UK, 2003.

[17] J. Lees, "Evaluating magnetic parameters for use in source identification, classification and modelling for natural and environmental materials," in Environmental Magnetism: A Practical Guide, J. Walden, F. Oldfield, and J. P. Smith, Eds., pp. 113-138, Quaternary Research Association, Cambridge, UK, 1999.

[18] J. A. Dearing, "Natural magnetic tracers in fluvial geomorphology," in Tracers in Geomorphology, I. D. L. Foster, Ed., pp. 57-82, John Wiley \& Sons, London, UK, 2000.

[19] P. Kearey and M. Brooks, An Introduction to Geophysical Exploration. Geoscience Texts, Blackwell Science, London, UK, 2nd edition, 1998.

[20] S. Treitle, W. C. Clement, and R. K. Kaul, "Specteral determination of depth to buried magnetic basement rocks," Geophysical Journal of the Royal Astronomical Society, vol. 24, no. 4, pp. 415-428, 1971.

[21] M. Muniruzzaman and R. J. Banks, "Basement magnetization estimates by wavenumber domain analysis of magnetic and gravity maps," Geophysical Journal, vol. 97, no. 1, pp. 103-117, 1989.

[22] A. Spector and F. S. Grant, "Statistical models for interpreting aeromagnetic data," Geophysics, vol. 34, no. 1, pp. 193-302, 1970.
[23] H. S. Sadek, "Profile frequency analysis of potential field data using filon fourier transform, with basic software," in Proceedings of the 5th International Seminar on Model optimization in Exploration Geophysics, Free University of Berlin, 1987.

[24] H. R. Burger, Exploration Geophysics of the Shallow Subsurface, Prentice Hall International, London, UK, 1992.

[25] D. H. Griffiths and R. F. King, Applied Geophysics for Geologists and Engineers. The Elements of Geophysical Prospecting, Pergamon Press Ltd., Headington Hill Hall, Oxford OX30BW, England, UK, 1981.

[26] W. Lowrie, Fundamentals of Geophysics, Cambridge University press, 1997.

[27] D. S. Parasnis, Principles of Applied Geophysics, Chapman and Hall, A Halsted Press Book, London, UK, 3rd edition, 1979. 

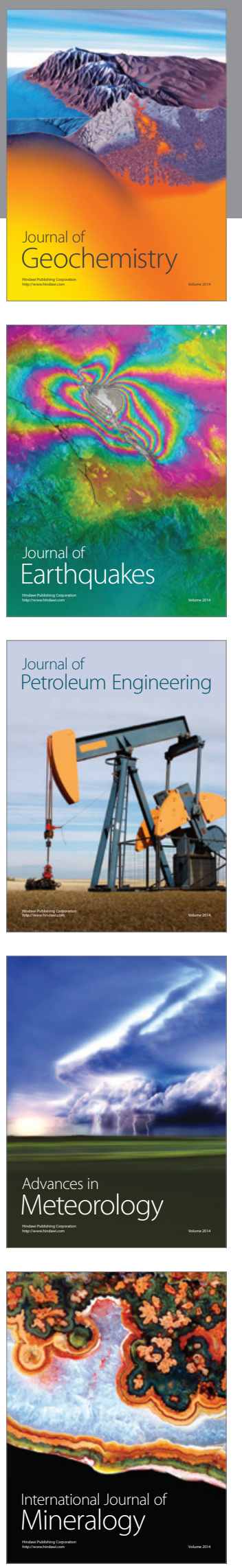
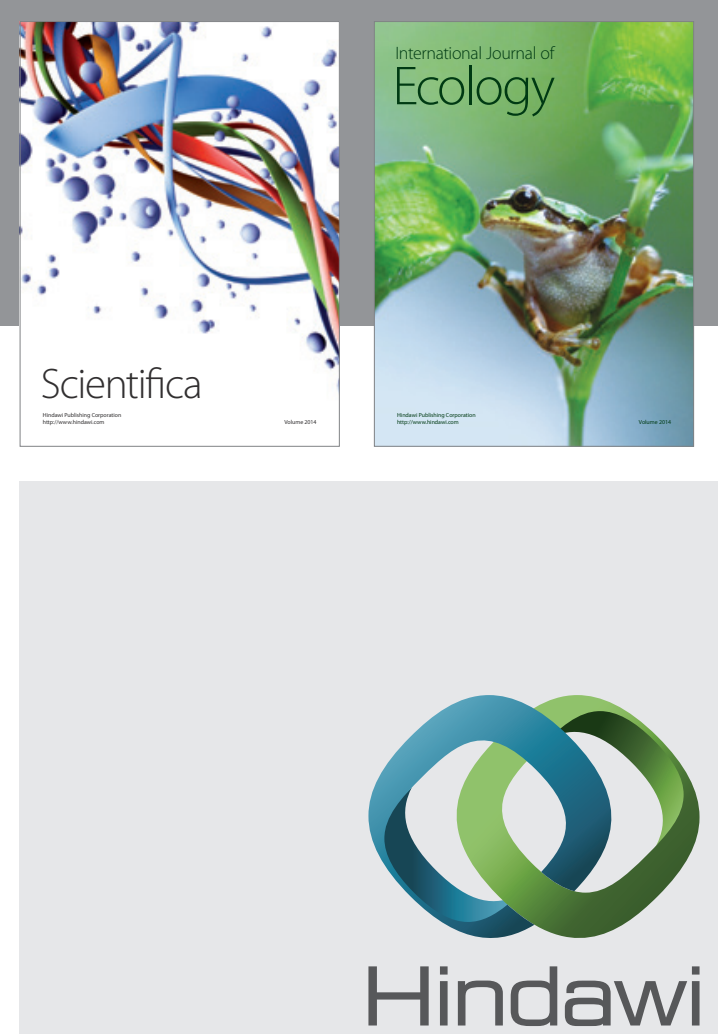

Submit your manuscripts at http://www.hindawi.com
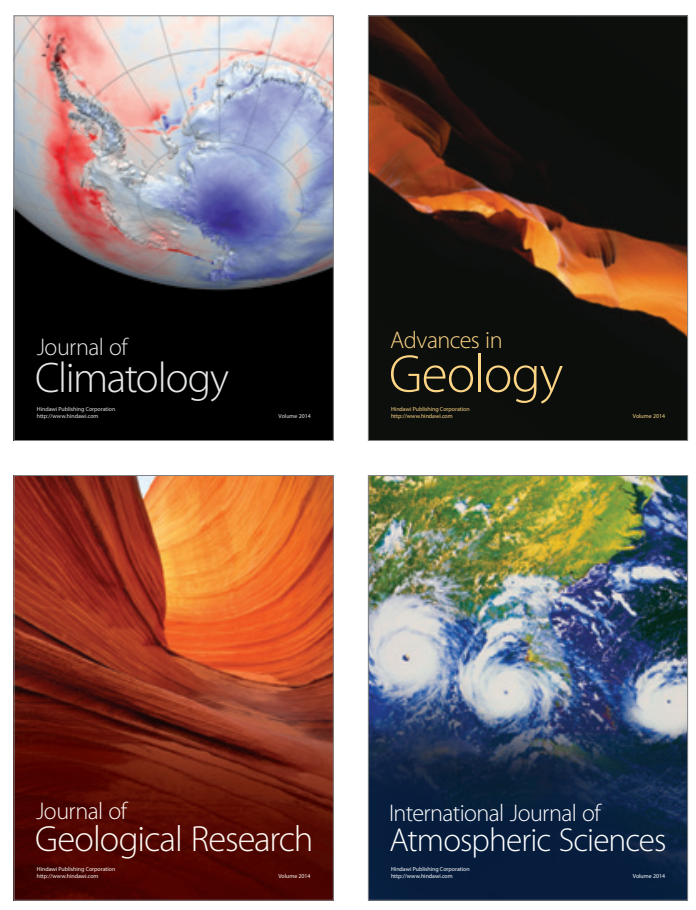
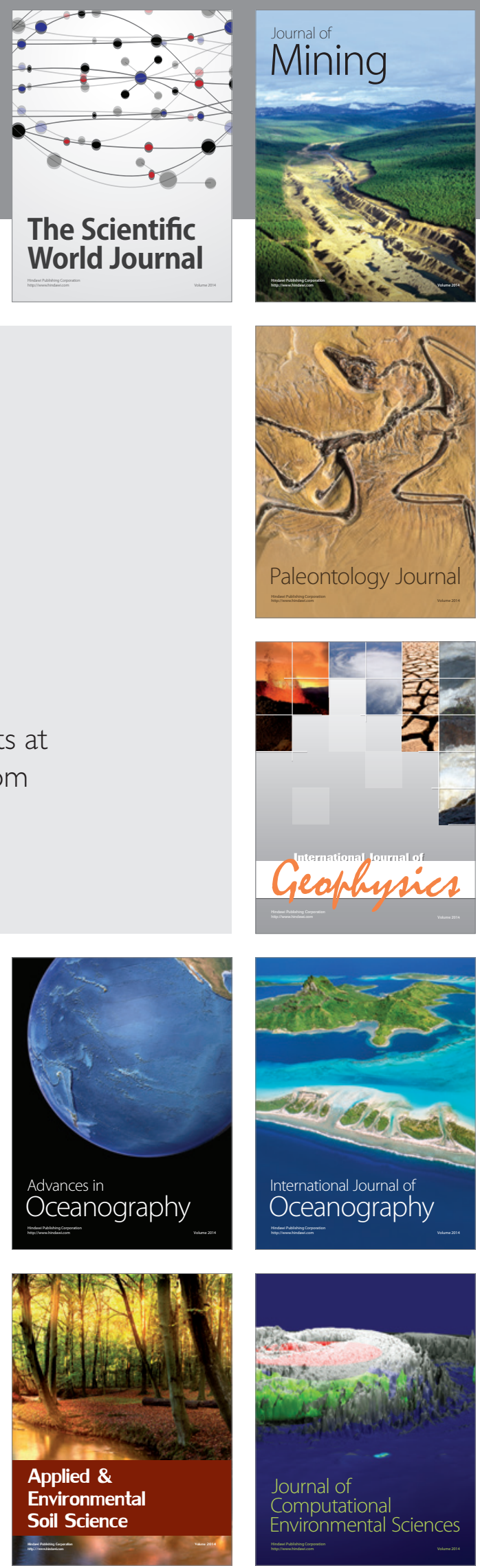